\title{
ЭКТОДЕРМАЛЬНАЯ ДИСПЛАЗИЯ. СИСТЕМАТИЧЕСКИЙ ОБЗОР
}

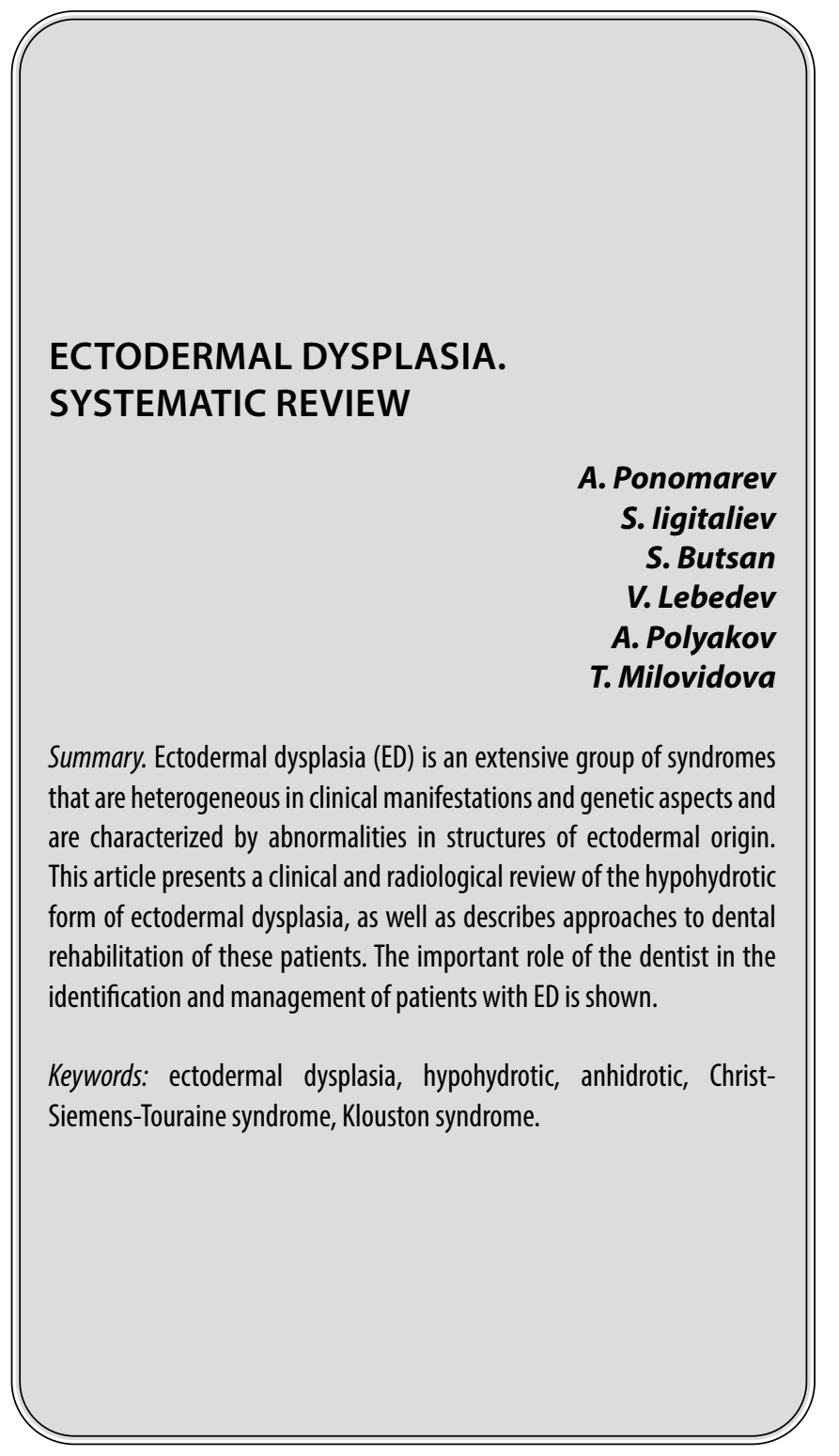

\section{Введение}

\section{Терминология и классификация}

$\mathbf{T}$ ермин «эктодермальная дисплазия» (ЭД) объединяет в себе группу наследственных заболеваний, характеризующихся структурными и функциональными аномалиями тканей, происходящих из эктодермы [1]. Впервые определение и классификация эктодермальных дисплазий были предложены Freire Maia $(1971 ; 1977)[2,3]$. Авторы выделяют две группы. К группе А относятся нозологии с дефектами как минимум в двух следующих «классических» структурах: волосы, зубы,
Пономарев Артемий Эрнестович

Врач челюстно-лицевой хирург, Центральный научно-исследовательский институт стоматологии

и челюстно-лицевой хирургии Минздрава России ponomarev_100@list.ru

Йигиталиев Шухрат Нуманович

К.м.н., врач челюстно-лицевой хирург, Центральный научно-исследовательский институт стоматологии и челюстно-личевой хирургии Минздрава России

Буцан Сергей Борисович

К.м.н., врач челюстно-личевой хирург, Центральный научно-исследовательский институт стоматологии и челюстно-лицевой хирургии Минздрава России

Лебедев Валентин Витальевич

Врач челюстно-личевой хирург, Центральный научно-исследовательский институт стоматологии и челюстно-лицевой хирургии Минздрава России

Поляков Александр Владимирович

Д.б.н., профессор, Член-корреспондент РАН, Медикогенетический научный чентр имени академика

Н.П. Бочкова

Миловидова Татьяна Борисовна

Н.с., Медико-генетический научный центр имени академика Н.П. Бочкова

Аннотация. Эктодермальные дисплазии (ЭД) представляют собой обширную группу синдромов, неоднородных по клиническим проявлениям и генетическим аспектам и характеризующихся аномалиями в структурах эктодермального происхождения. В настоящей статье представлен клинико-рентгенологический обзор гипогидротической формы эктодермальной дисплазии, а также описаны подходы к стоматологической реабилитации данных больных. Показана важная роль стоматолога в идентификации и ведении пациентов с ЭД.

Ключевые слова: эктодермальная дисплазия, гипогидротическая, ангидротическая, синдром Криста-Сименса-Турена, синдром Клоустона.

ногти и потовые железы, с пороками развития и другими дефектами или без них. К группе В относятся нозологии с дефектами только в одной из четырех вышеупомянутых структур. Состояние, характеризуемое только эктодермальными признаками, называется «чистой» ЭД. Если патологический процесс сочетает в себе эктодермальные признаки и пороки развития, это называется синдромальной ЭД. Однако позднее была предложена другая классификация, в основу которой легли знания о молекулярно-генетических механизмах и биологических функциях белков, участвующих в развитии ЭД. Manuela Priolo (2001) и Carmelo Laganà (2009) выделили две группы ЭД $[4,5]$. К первой группе они отнесли «чи- 
стые» ЭД, возникающие в результате дефектов регуляции развития или эпителиально-мезенхимального взаимодействия. Например, Х-сцепленная гипогидротическая эктодермальная дисплазия 1 (ОМІМ 305100). Ко второй группе относятся нозологии, причиной которых являются дефекты в структурных белках цитоскелета. Например, эктодермальная дисплазия 2, тип Клоустона (ОМІМ 129500). Для ЭД описаны все известные типы наследования: аутосомно-доминантный, аутосомно-рецессивный, Х-сцепленный.

\section{Клинические примеры наиболее распространенной ЭД:}

На сегодняшний день описано более 150 различных ЭД с известной молекулярной причиной. Две наиболее распространенные формы - гипогидротическая ЭД и гидротическая ЭД. Распространенность всех типов ЭД составляет 21.9 на 100000 новорожденных. Гипогидротическая форма является наиболее распространенной и составляет 90\% всех эктодермальных дисплазий[6].

\section{Гипогидротическая эктодермальная дисплазия (ГЭД) (синдром Криста-Сименса-Турена) - 90\%}

Наиболее частой формой ЭД является гипогидротическая эктодермальная дисплазия (ГЭД), характеризующаяся триадой признаков: 1) гипотрихоз (или атрихоз); 2) гиподонтия (анодонтия); 3) гипогидроз (или ангидроз), который может сопровождаться угрожающей жизни гипертермией [7]. Термин «гипогидротическая» ЭД предпочтительнее «ангидротической» ЭД, так как обычно нет полного отсутствия потовых желез [8]. Ранее было показано, что мутации в четырех генах (EDA, EDAR, EDARADD и WNT10A) ответственны за приблизительно 90\% случаев ГЭД [9]. Гипогидротическая эктодермальная дисплазия характеризуется такими фенотипическими особенностями лица как выступающий вперед лобные бугры, редкие, тонкие, зачастую отсутствующие брови и волосы, редкие дистрофичные ресницы. Пигментация волос часто отсутствует. Имеется частичная или полная адентия. Слизистые оболочки сухие, кожа мягкая, сухая, с мелкими складками, морщинки под глазами, характерная периорбитальная гиперпигментация, большие выступающие уши, выпяченные утолщенные губы, седловидная переносица и гипоплазия челюстей. Заболевание существует с рождения или развивается в течение первого года жизни. При гистологическом исследовании биоптата кожи отмечается атрофия эпидермиса, потовые железы не обнаруживаются или определяются их рудименты, может встречаться гипоплазия волосяных фолликулов и сальных желез [10]. Аутосомно-доминантная и аутосомно-рецессивная формы встречаются в равной степени у представителей обоих полов. В случае X-сцепленной формы, у носителей женского пола заболевание может протекать бессимптомно или в более легкой форме: при осмотре возможно выявить олигодонтию, деформацию резцов по типу конической формы, гипотрихоз, умеренный гипогидроз и трудности в грудном вскармливании вследствие порока развития грудных желёз [11, 12]. Аллельным (гомогенным) вариантом Х-ГЭД является селективная агенезия зубов с Х-сцепленным доминантным типом наследования, основным клиническим признаком которой является олиго- или гиподонтия.

На Х-сцепленную форму ГЭД (Х-ГЭД, синдром Криста-Сименса-Турена) приходится до 95\% всех случаев ГЭД [13]. Распространенность Х-ГЭД составляет 1 на 17 000 новорожденных [14]. Причиной развития Х-ГЭД являются различные мутации гена EDA, расположенного на длинном плече Х-хромосомы (Хq12-q13.1) и кодирующем трансмембранный белок, эктодисплазин-А, экспрессирующийся в кератиноцитах, волосяных фолликулах и потовых железах и играющий ключевую роль в эпителиально-мезенхималной передаче сигнала [15]. Ген EDA (MN_001399.4) состоит из 8 экзонов. В настоящее время описано более 330 мутаций в этом гене, включая крупные делеции и инсерции. Основной тип мутаций - точковые (миссенс и нонсенс варианты). На их долю по данным базы данных HGMD ${ }^{\circledR}$ Professional версия 2019.3 приходится около 55\%. На долю небольших делеций и инсерций, а также мутаций сайта сплайсинга приходится около $25 \%$ и $9 \%$ соответственно от всех мутаций гена EDA. На долю крупных делеций и инсерций выпадает $11 \%$ всех мутаций гена EDA.

В настоящее время доступны как прямая так и косвенная ДНК-диагностика Х-ГЭД, заключающаяся в поиске мутаций в гене EDA методом прямого автоматического секвенирования и анализе сцепления высокоплиморфных генетических маркеров, расположенных в локусе гена EDA методом полиморфизма длин амплификационных фрагментов. Однако в некоторых случаях данных методов бывает недостаточно для выявления мутации или для определения носительства мутантного гена у женщин. Так, например, у матерей, для сыновей которых была выявлена делеция/дупликация всего гена EDA или его части, невозможно с помощью секвенирования определить носительство мутации вследствие наличия второй интактной Х-хромосомы. В этом случае показано определения числа копий гена EDA методом количественной мультиплексной лигазной реакции. В случае установленной молекулярной причины Х-ГЭД в отягощенных семьях возможно проведение дородовой диагностики для прогноза потомства.

\section{Гидротическая ЭД (синдром Клоустона) - 10\% от всех ЭД}

Синдром Клоустона - крайне редкое наследственное заболевание, основными признаками которого явля- 


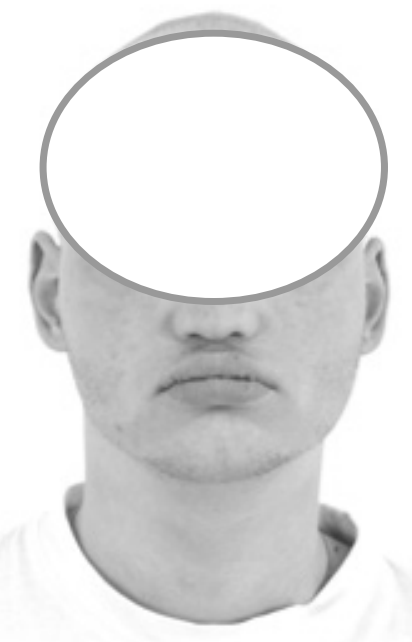

Пациент·A

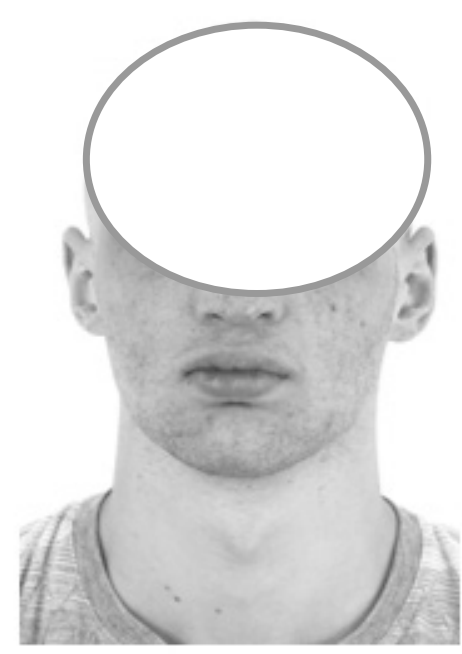

Пациент·В

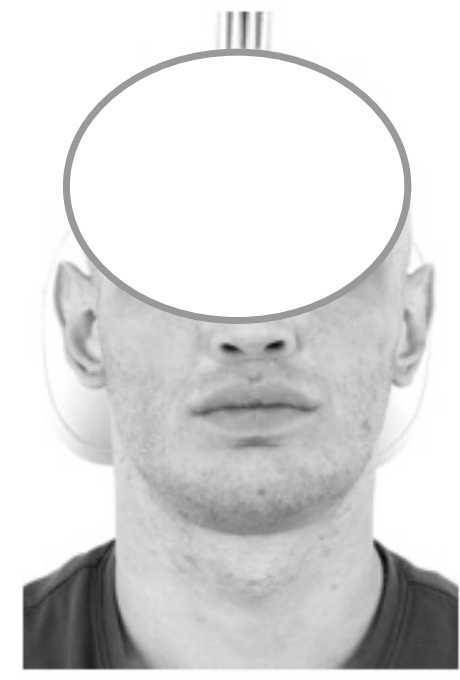

Пациент ·

Рис. 1. Фото в фас

ются дистрофия ногтей и гипотрихоз различной степени выраженности. Ногти гипопластичны и деформированы с повышенной восприимчивостью к паронихиальным инфекциям. Дефекты волос варьируют от ломкости и медленной скорости роста до полной алопеции. Отмечается умеренный или тяжелый пальмоплантарный гиперкератоз и лейкоплакия в полости рта вследствие редуцированной десквамации кератиноцитов. У пациентов повышена склонность к кариесу, наблюдается гиперпигментация в области суставов. Функция потовых и сальных желёз не нарушена. При гистологическом исследовании биоптата кожи регистрируют незначительную атрофию эпидермиса, гиперкератоз, отсутствие или недоразвитость волосяных фолликулов, потовые железы определяются в нормальных количествах [10]. Аллельным (гомогенным) вариантом синдрома Клоустона является тугоухость с аутосомно-доминантным (тип 3В) или аутосомно-рецессивным (тип 1В) типом наследования, основным клиническим проявлением которой является двусторонняя потеря слуха и вестибулярная дисфункция (у некоторых пациентов).

Причиной развития синдрома Клоустона являются различные мутации гена GJB6, расположенного на длинном плече хромосомы 13 (13q12.11) и кодирующего белок щелевого контакта коннексин-30, экспрессирующийся в головном мозге, улитке и эпителии и играющий ключевую роль в пролиферации и дифференцировке клеток [16]. Ген GJB6 состоит из 3 экзонов, первый и второй экзоны являются некодирующими. В настоящее время в гене GJB6 описано 34 мутации. Однако на долю патогенных вариантов, приводящих к синдрому Клоустона, приходится всего 20,5\% и все они представлены мис- сенс-вариантиами. Остальные 79,5\% мутаций, включая крупные делеции, описаны при тугоухости. В настоящее время доступна прямая ДНК-диагностика синдрома Клоустона, заключающаяся в поиске мутаций в гене GJB6 методом прямого автоматического секвенирования. В случае установленной молекулярной причины синдрома Клоустона в отягощенных семьях возможно проведение дородовой диагностики для прогноза потомства.

\section{Материалы и метомы}

На базе отделения челюстно-лицевой хирургии ФГБУ «ЦНИИС и ЧЛХ» г. Москва Минздрава России находились на лечении и реабилитации 10 пациентов в период с 2014-2019 г. 8 мужчин и 2 женщины, возрастом от 1928 лет.

Все пациенты с подтвержденным диагнозом: «Эктодермальная дисплазия (гипогидротическая форма), с частичной или полной адентией верхней и нижней челюстей. Недоразвитием верхней и нижней челюстей» (МКБ X: Q82.4, K00.0, K07.0).

На основании клинических, рентгенологических и компьютерных методов (3D-цефалометрия) исследования проведен сравнительный анализ пациентов с ЭД.

У пациентов с гипогидротической формой ЭД характеризуются триадой симптомов: гипотрихоз (или атрихоз), гиподонтия (анодонтия) и гипогидроз (или ангидроз), который может сопровождаться угрожающей жизни гипертермией (при определенных погодных ус- 


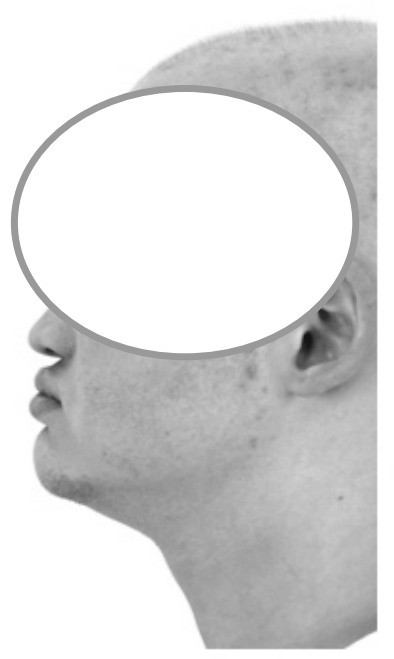

Пациент А

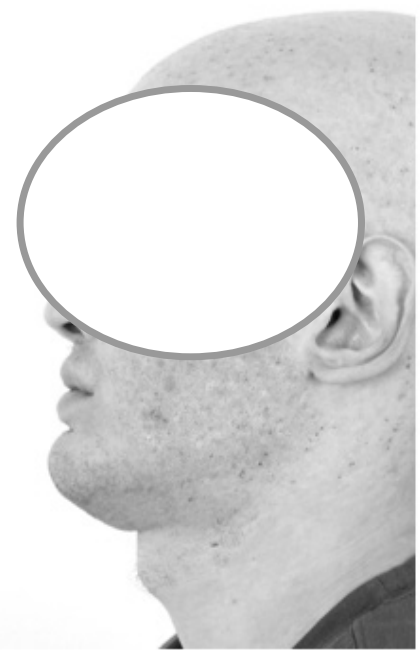

Пациент В

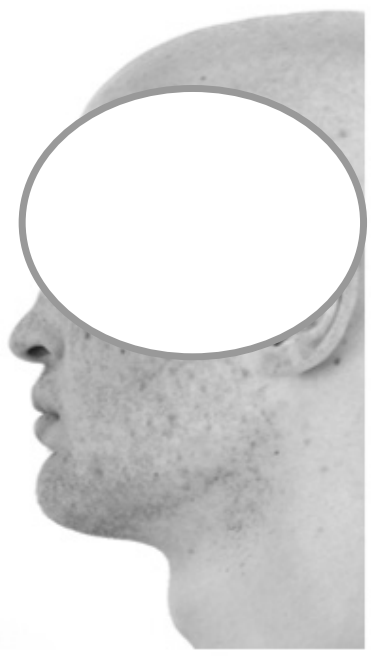

Пациент С

Рис. 2. Фото в профиль

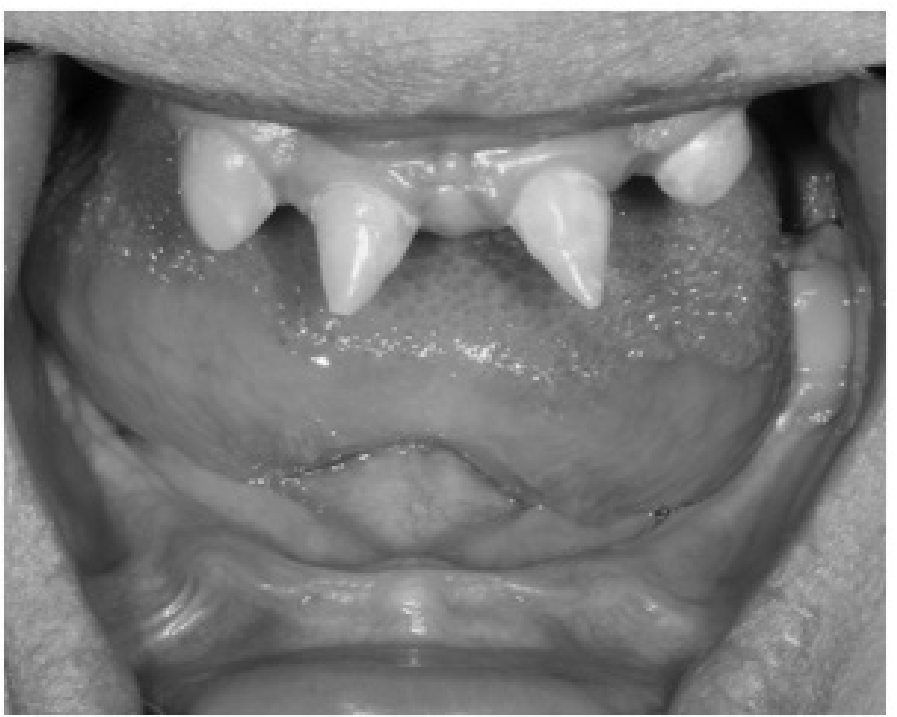

Рис. 3. Фото полости рта

ловиях). Отмечаются ломкие, пушистые волосы на голове, гиперкератоз выражен незначительно, недоразвитые волосяных фолликулы в надбровных областях (волосы редкие). Все пациенты очень схожи между собой.

В профиль отмечается верхнечелюстная и нижнечелюстная гипоплазия, нижнечелюстная прогнатия, также соотношение челюстей по II и III классу Энгля, как сагиттальной, так и во фронтальной плоскостях, снижением высоты прикуса, выраженная подбородочная складка, подбородок выступает вперед и вверх - данные признаки можно сравнить со старческими проявлениями челюстно - лицевой области.
В полости рта наиболее явным признаком является первичная олигодонтия, отсутствие 6 и более зубов включая 3-и моляры.

У всех пациентов отмечается отсутствие, клыков, премоляров и третьих моляров на верхней челюсти, аномальное расположение центральных резцов отмечается у двух пациентов, аномальная форма центрального и латерального резца у трех пациентов, наличие временных зубов на верхней и нижней челюсти у трех пациентов. Отсутствие резцов, клыков и первых премоляров у двух пациентов, отсутствие резцов и первых премоляров у одного пациента. 
Таблица 1. Количество временных и постоянных зубов

\begin{tabular}{|c|c|c|c|c|c|c|}
\hline $\begin{array}{l}\text { № } \\
\text { Пациента }\end{array}$ & $\begin{array}{l}\text { Количество } \\
\text { временных } \\
\text { зубов на } \\
\text { верхней } \\
\text { челюсти }\end{array}$ & $\begin{array}{l}\text { Количество } \\
\text { временных } \\
\text { зубов на } \\
\text { нижней } \\
\text { челюсти }\end{array}$ & $\begin{array}{l}\text { Общее } \\
\text { количество } \\
\text { временных } \\
\text { зубов }\end{array}$ & $\begin{array}{l}\text { Количество } \\
\text { постоянных } \\
\text { зубов на } \\
\text { верхней } \\
\text { челюсти }\end{array}$ & $\begin{array}{l}\text { Количество } \\
\text { постоянных } \\
\text { зубов на } \\
\text { нижней } \\
\text { челюсти }\end{array}$ & $\begin{array}{l}\text { Общее } \\
\text { количество } \\
\text { постоянных } \\
\text { зубов }\end{array}$ \\
\hline 1 & 0 & 0 & 0 & 4 & 1 & 5 \\
\hline 2 & 1 & 4 & 5 & 2 & 2 & 4 \\
\hline 3 & 0 & 0 & 0 & 3 & 0 & 3 \\
\hline 4 & 6 & 3 & 9 & 3 & 2 & 5 \\
\hline 5 & 0 & 0 & 0 & 10 & 6 & 16 \\
\hline 6 & 1 & 0 & 1 & 8 & 8 & 16 \\
\hline 7 & 4 & 1 & 5 & 4 & 7 & 11 \\
\hline 8 & 4 & 0 & 4 & 4 & 2 & 6 \\
\hline 9 & 0 & 0 & 0 & 2 & 0 & 2 \\
\hline 10 & 0 & 0 & 0 & 1 & 2 & 3 \\
\hline 11 & 3 & 2 & 5 & 2 & 2 & 4 \\
\hline
\end{tabular}

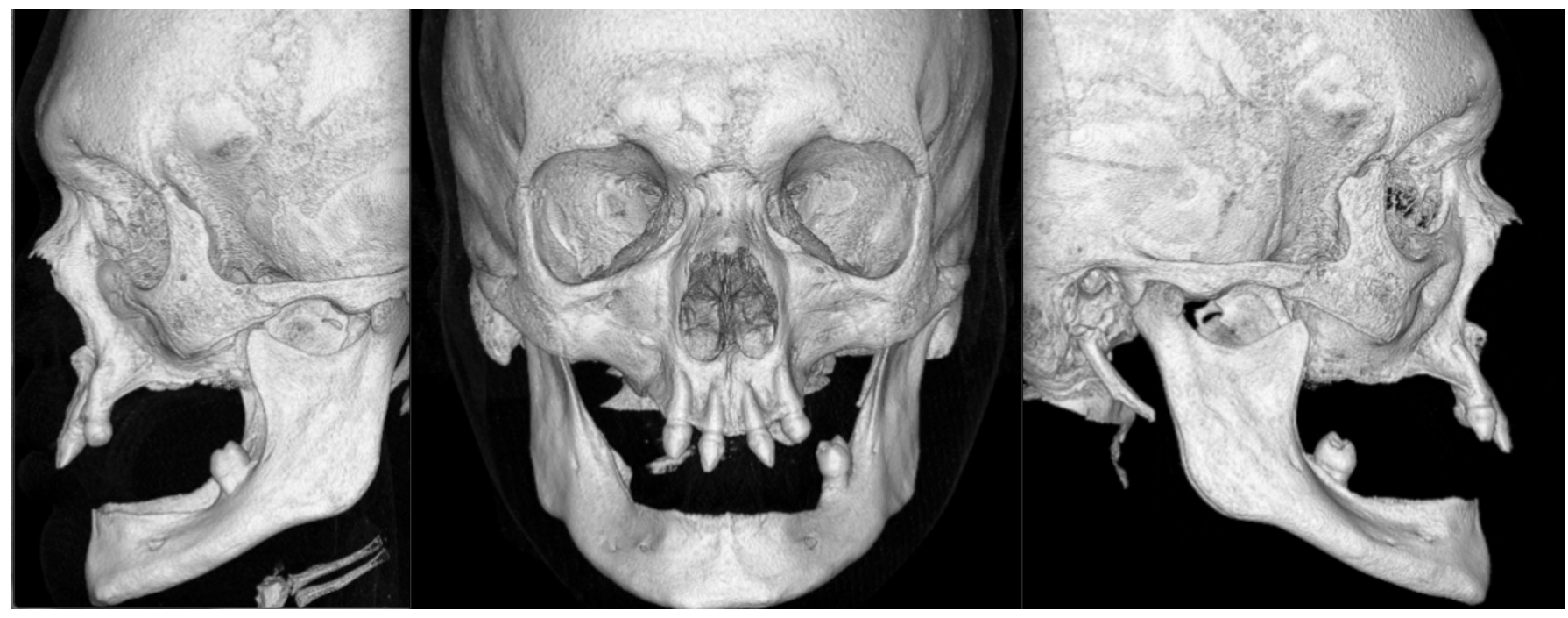

Рис. 4. Скрин-карточка компьютерной томографии

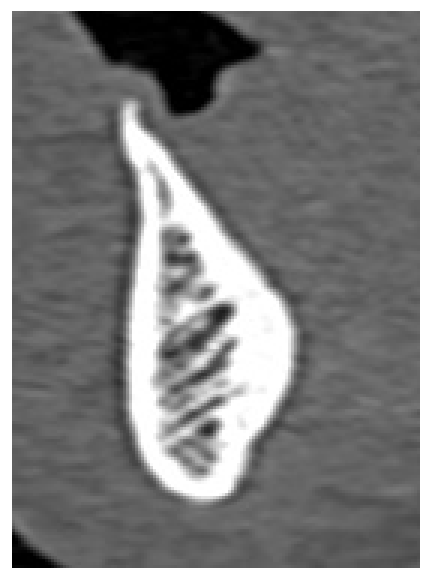

Рис. 5. Фронтальный срез мскт 
Таблица 2. Показатели плотности в единицах Хаунсфилда

\begin{tabular}{|l|l|l|l|}
$\begin{array}{l}\text { № } \\
\text { Пациента }\end{array}$ & $\begin{array}{l}\text { Минимальное значение } \\
\text { плотности (hu) }\end{array}$ & $\begin{array}{l}\text { Максимальное значение } \\
\text { плотности (hu) }\end{array}$ & $\begin{array}{l}\text { Среднее значение плотности } \\
\text { (hu) }\end{array}$ \\
\hline 1 & 193 & 1802 & 1609 \\
\hline 2 & 201 & 1770 & 1569 \\
\hline 3 & 230 & 1820 & 1590 \\
\hline 4 & 200 & 1678 & 1478 \\
\hline 5 & 198 & 1700 & 1502 \\
\hline 6 & 201 & 1750 & 1549 \\
\hline 7 & 202 & 1688 & 1486 \\
\hline 8 & 200 & 1670 & 1470 \\
\hline 9 & 199 & 1710 & 1511 \\
\hline 10 & 196 & 1680 & 1484 \\
\hline 11 & 204 & 1655 & 1451 \\
\hline
\end{tabular}

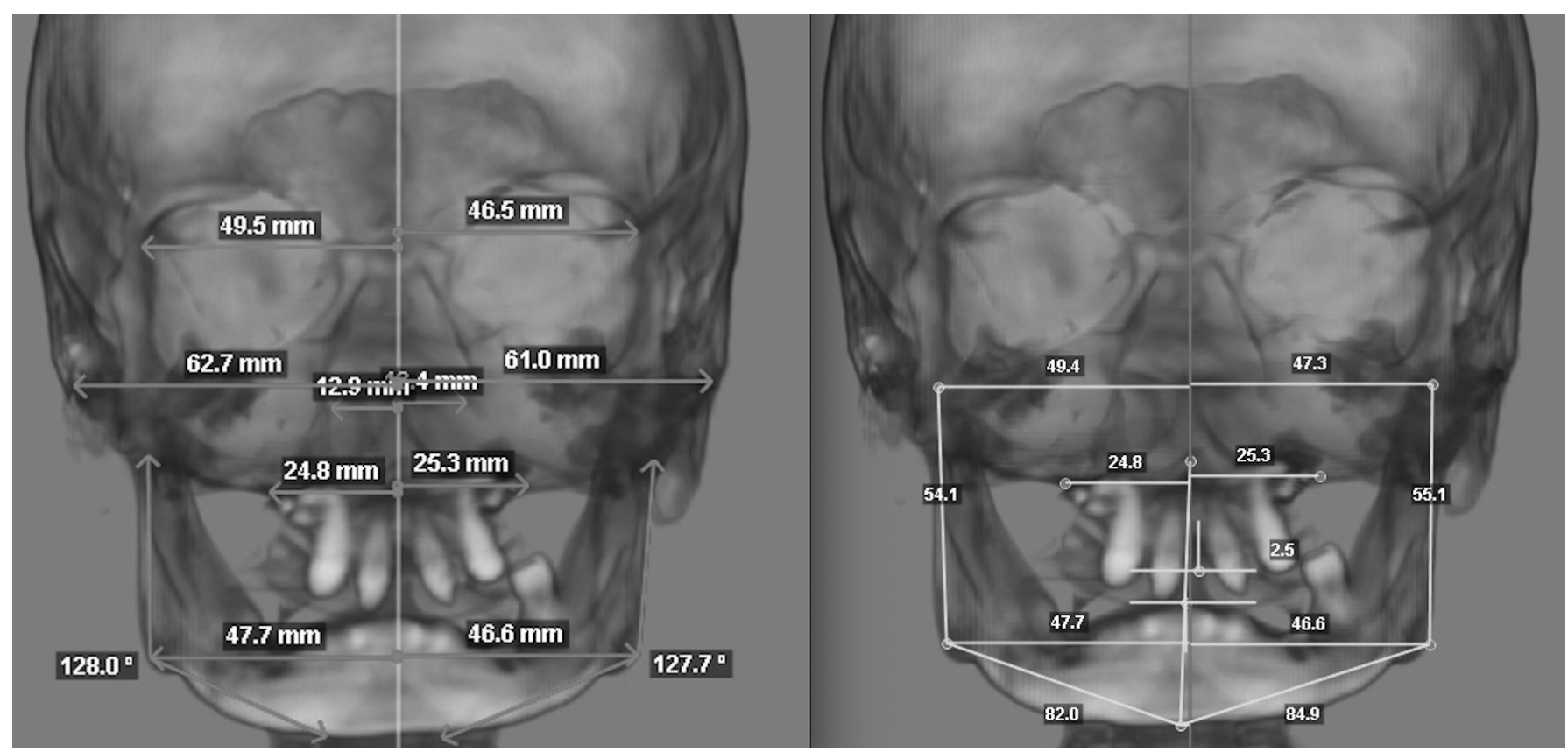

Рис. 6. 3D цефалометрическое исследование

Эмаль также может быть дефектной. Наблюдается широкая срединная диастема.

По данным рентгенологического и компьютерного исследования отмечается гипоплазированая костная ткань на верхней и нижней челюсти в зонах отсутствующих зубов, альвеолярный гребень на верхней и нижней челюсти характерной заостренной формы.

Исследуя биотип костной ткани на основании компьютерной томографии, определяют минимальное и максимальное значение плотности биологической ткани в единицах по шкале Хаунсфилда (согласно программе «Amira 3D Reconstruction»).
Среднее значение плотности костной ткани у всех трех пациентов соответствует типу - D1 (при норме плотных структур равной от $1455 \mathrm{HU})$.

На основании проведенного 3D цефалометрического анализа челюстно-лицевой области у пациентов с гипогидротической формой ЭД отмечается (пример исследования одного из пациентов):

\section{Cкелетные \\ параметры}

Межапикальный угол (<ANB) -5.4 deg, что соответствует соотношению челюстей по скелетному 3 классу. 
Таблица 3. Этапы реабилитации пациентов

\begin{tabular}{|c|c|c|c|c|c|c|}
\hline $\begin{array}{l}\text { № } \\
\text { Паци- } \\
\text { ента }\end{array}$ & $\begin{array}{l}\text { Удаление не } \\
\text { состоятельных } \\
\text { зубов }\end{array}$ & $\begin{array}{l}\text { Костная } \\
\text { пластика } \\
\text { (Аугментация) }\end{array}$ & Синуслифтинг & $\begin{array}{l}\text { Дентальная } \\
\text { имплантация/ } \\
\text { количество }\end{array}$ & $\begin{array}{l}\text { Ортогнатиче- } \\
\text { ская хирургия }\end{array}$ & $\begin{array}{l}\text { Протезирование } \\
\text { с опорой на } \\
\text { дентальные } \\
\text { имплантаты }\end{array}$ \\
\hline 1 & - & + & + & $+/ 8$ & 0 & 0 \\
\hline 2 & + & + & + & $+/ 8$ & 0 & 0 \\
\hline 3 & + & + & + & $+/ 12$ & - & + \\
\hline 4 & + & + & + & $+/ 9$ & - & + \\
\hline 5 & - & + & + & $+/ 8$ & + & + \\
\hline 6 & + & + & + & $+/ 10$ & + & 0 \\
\hline 7 & + & + & + & $+/ 10$ & 0 & 0 \\
\hline 8 & + & + & + & $+/ 7$ & - & + \\
\hline 9 & - & + & + & $+/ 12$ & - & + \\
\hline 10 & - & + & + & $+/ 12$ & - & + \\
\hline 11 & + & + & + & $+/ 12$ & - & + \\
\hline
\end{tabular}

«-»- не проводилось; «+»-проводилось; «0»-планируется

\section{Положение головок и углов нижней челюсти}

\begin{tabular}{c|c|c|c|c}
\hline $\begin{array}{c}\text { Mandibular Angle Position - Gonion } \\
\text { to Anterior Facial Plane, R(mm) }\end{array}$ & 60,6 & 69,0 & 7,0 & $-1,2$ \\
\hline $\begin{array}{c}\text { Mandibular Angle Position - Gonion } \\
\text { to Anterior Facial Plane, L(mm) }\end{array}$ & 62,0 & 69,0 & 7,0 & $-1,0$ \\
\hline $\begin{array}{c}\text { Mandibular Angle Position - Gonion } \\
\text { to Superior Facial Plane, R(mm) }\end{array}$ & 84,2 & 82,0 & 7,0 & 0,3 \\
\hline $\begin{array}{c}\text { Mandibular Angle Position - Gonion } \\
\text { to Superior Facial Plane, L(mm) }\end{array}$ & 84,3 & 82,0 & 7,0 & 0,3 \\
\hline Gonion to Midsagittal plane, R(mm) & $-47,7$ & 45,0 & 3,0 & $-0,8$ \\
\hline Gonion to Midsagittal plane, L (mm) & 46,6 & 45,0 & 3,0 & 0,5 \\
\hline Gonial Width (mm) & 94,4 & 90,0 & 7,0 & 0,6 \\
\hline $\begin{array}{c}\text { Condyle Position - Condlyion to } \\
\text { Superior Facial Plane, R(mm) }\end{array}$ & 33,2 & 25,0 & 5,0 & 1,6 \\
\hline $\begin{array}{c}\text { Condyle Position - Condlyion to } \\
\text { Superior Facial Plane, L (mm) }\end{array}$ & 32,7 & 25,0 & 5,0 & 1,5 \\
\hline $\begin{array}{c}\text { Condyle Position - Condlyion to } \\
\text { Anterior Facial Plane, R(mm) }\end{array}$ & 78,8 & 80,0 & 5,0 & $-0,2$ \\
\hline $\begin{array}{c}\text { Condyle Position - Condlyion to } \\
\text { Anterior Facial Plane, L(mm) }\end{array}$ & 81,5 & 80,0 & 5,0 & 0,3 \\
\hline $\begin{array}{c}\text { Condilyion to Midsagittal plane, R } \\
\text { (mm) }\end{array}$ & $-49,4$ & 49,0 & 3,0 & 0,1 \\
\hline $\begin{array}{c}\text { Condlyion to Midsagittal plane, L } \\
\text { (mm) }\end{array}$ & 47,3 & 49,0 & 3,0 & $-0,6$ \\
\hline \begin{tabular}{c} 
Condlyion Width (mm) \\
\hline
\end{tabular} & 96,7 & 98,0 & 7,0 & $-0,2$
\end{tabular}

Рис. 7. Показатели 3D цефалометрического исследования (продолжение на стр. 201) 


\section{Угловые параметры}

\begin{tabular}{c|c|c|c|c|}
\hline Palatal Plane PNS-ANS $\left(^{\circ}\right)$ & 3,1 & 3,0 & 3,0 & $-0,1$ \\
\hline Occlusal Plane $\left(^{\circ}\right)$ & 11,2 & 8,0 & 3,0 & 1,1 \\
\hline Mandibular Plane, $\mathrm{R}\left({ }^{\circ}\right)$ & 13,7 & 21,0 & 3,0 & $-2,4$ \\
\hline Mandibular Plane, $\mathrm{L}\left({ }^{\circ}\right)$ & 13,3 & 21,0 & 3,0 & $-2,6$ \\
\hline SNA $\left(^{\circ}\right)$ & 78,2 & 82,0 & 3,0 & $-1,3$ \\
\hline SNB $\left(^{\circ}\right)$ & 84,8 & 80,0 & 3,0 & 1,6 \\
\hline ANB (deg) & $-6,7$ & 2,0 & 2,0 & $-4,4$ \\
\hline Wits Apprsl, (mm) & & $-0,4$ & 2,5 & 0,2 \\
\hline Beta Angle (deg) & 43,7 & 31,0 & 4,0 & 3,2 \\
\hline Ar-Go-Me (R)(deg) & 128,0 & 130,0 & 5,0 & $-0,4$ \\
\hline Ar-Go-Me (L) (deg) & 127,7 & 130,0 & 5,0 & $-0,5$ \\
\hline Interincisal angle (U1-L1) (R) & & 130,0 & 8,0 & $-16,3$ \\
\hline Interincisal angle (U1-L1) (L) & & 130,0 & 8,0 & $-16,3$ \\
\hline U1-Palatal Plane (deg) (R) & 112,7 & 110,0 & 5,0 & 0,5 \\
\hline U1-Palatal Plane (deg) (L) & 113,8 & 110,0 & 5,0 & 0,8 \\
\hline L1-MP (deg) (R) & & 95,0 & 5,0 & $-19,0$ \\
\hline L1-MP (deg) (L) & & 95,0 & 5,0 & $-19,0$ \\
\hline
\end{tabular}

\section{Линейные параметры}

\begin{tabular}{c|c|c|c|c}
\hline Sna-Snp (mm) & 47,4 & 56,1 & 4,3 & $-2,0$ \\
\hline A-Snp (mm) & 45,0 & 51,0 & 3,5 & $-1,7$ \\
\hline Go-Me, R (mm) & 82,0 & 86,0 & 5,0 & $-0,8$ \\
\hline Go-Me,L (mm) & 84,9 & 86,0 & 5,0 & $-0,2$ \\
\hline Co-Go,R (mm) & 54,1 & 66,0 & 3,9 & $-3,1$ \\
\hline Co-Go,L (mm) & 55,1 & 66,0 & 3,9 & $-2,8$ \\
\hline N-S (mm) & 72,8 & 71,0 & 3,0 & 0,6 \\
\hline N-Me (Total facial height) (mm) & 100,3 & 118,0 & 6,0 & $-3,0$ \\
\hline (H)Zy-Zy (mm) & 123,8 & 130,0 & 6,0 & $-1,0$ \\
\hline (H)N-Mel(H)Zy-Zy (\%) & 81,0 & 91,0 & 6,0 & $-1,7$ \\
\hline
\end{tabular}

Положение верхней челюсти

\begin{tabular}{c|c|c|c|c}
\hline $\begin{array}{c}\text { (H) Maxillary position at A point (AP) } \\
(\mathrm{mm})\end{array}$ & $-1,5$ & 0,0 & 2,0 & $-0,8$ \\
\hline $\begin{array}{c}\mathrm{H}) \text { Maxillary position at A point } \\
\text { (vertically) (mm) }\end{array}$ & 53,7 & 54,0 & 3,0 & $-0,1$ \\
\hline $\begin{array}{c}\mathrm{H}) \text { Maxillary position at A point } \\
\text { (sagittally) (mm) }\end{array}$ & 0,7 & 0,0 & 0,0 & 0,7 \\
\hline Maxillary Width (J-J) (mm) & 50,2 & 62,0 & 3,0 & $-3,9$ \\
\hline Maxillary Cant (J-J) (mm) & 1,5 & 0,0 & 0,0 & 1,5 \\
\hline
\end{tabular}

Положение нижней челюсти

\begin{tabular}{c|c|c|c|c}
\hline (H) Mandibular position at Pg (AP) & 9,9 & 0,0 & 2,0 & 5,0 \\
\hline $\begin{array}{c}(\mathrm{mm}) \\
\text { (H) Mandibular position at Pg } \\
\text { (vertically) (mm) }\end{array}$ & 95,8 & 100,0 & 6,0 & $-0,7$ \\
\hline $\begin{array}{c}\text { (H) Mandibular position at Pg } \\
\text { (sagittally) (mm) }\end{array}$ & $-1,4$ & 0,0 & 0,0 & $-1,4$ \\
\hline
\end{tabular}

Рис. 7 (продолжение). Показатели 3D цефалометрического исследования 
Угол Beta равен $45.1 \mathrm{deg}$ - соответствует 3 скелетному классу.

Параметр APDI, характеризующий дисплазию развития челюстей в сагиттальном направлении, равен 100.9 $\operatorname{deg}$ при $\mathrm{N}=81.4+\backslash$ - 5 deg, что указывает на наличие скелетного 3 класса.

\section{Размер и положение верхней челюсти}

Размер основания верхней челюсти (PNS-ANS) по сагиттали ниже нормы.

Сужение основания верхней (J-J) челюсти в трансверзальной плоскости- справа расстояние до срединной плоскости составляет 24,8 мм, слева - 25,3 мм. $\mathrm{N}=$ $31.0+\backslash-1.5$. Заднее положение верхней челюсти в сагиттальной плоскости относительно передне го основания черепа ( $<\mathrm{SNA}=78,2 \mathrm{deg}, \mathrm{N}=82+\backslash$ - 3) и нормальное положение.

\section{Размер и положение нижней челюсти}

Размеры тела нижней челюсти по сагиттали (GoМе) увеличены: справа - 92.8 мм, слева - 94.4 мм. (N= $86.0+\backslash-5)$.

Длина тела нижней челюсти справа на 1.6 мм меньше, чем слева. Ветвь справа на 4.8 мм больше, чем слева. Гониальный угол (< Ar\Go\Me) уменьшен: справа $115.1 \mathrm{deg}$ и слева $118.0 \mathrm{deg}$. Справа угол на $2.9 \mathrm{deg}$ меньше, чем слева. Прогнатия нижней челюсти в сагиттальной плоскости относительно переднего основания черепа - < SNB равен 88.0 deg при норме $80.0+\backslash-3$ deg. Прогнатия нижней челюсти относительно передней лицевой референтной плоскости.

У всех обследуемых пациентов по данным проведенного 3d цефалометрического исследования отмечается:

- скелетный 3 класс;

- горизонтальный тип роста;

- уменьшение размера основания верхней челюсти;

- уменьшение размера ветвей нижней челюсти; -антеинклинация нижней челюсти в вертикальной плоскости.

\section{Вемение пациентов с эА}

\section{Первичная диагностика ЭД в детском возрасте}

Чтобы установить степень заболевания у пациента с диагнозом гипогидротическая или гидротическая эктодермальная дисплазия, рекомендуются следующие оценки:
- Первоначальная оценка развивающегося зубного ряда обычно выполняется путем пальпации зубных альвеол младенцев, чтобы определить, присутствуют ли развивающиеся зубные зачатки (которые проявляются в виде выпуклостей в альвеоле).

- Стоматологические рентгенограммы для определения степени гиподонтии и гипоплазии верхней и нижней челюсти

- Проведение генетического исследования

\section{Лечение проявлений}

Ведение пациентов с гипогидротической или гидротической эктодермальной дисплазией направлено на три основных элемента:

- оптимизация психосоциального развития. Решение проблемы адаптации детей с ЭД является не простой, но очень важной задачей родителей, педагогов, психологов и социальных работников.

- создание адекватной функции полости рта. Лечение зубов, от простых реставраций до протезов, должно начинаться в раннем возрасте. Челюстно-лицевая хирургия, с целью зубо-челюстной реабилитации пациентов. Диетологическое консультирование может быть полезно тем людям, которые испытывают проблемы с жеванием и глотанием, несмотря на адекватную стоматологическую помощь. Заменители слюны и оптимальное воздействие фтора могут быть полезны для предотвращения кариеса у тех людей, у которых отмечается заметное снижение слюноотделения.

- симптоматическое лечение направлено на улучшение качества жизни пациентов: использование париков и косметологических средств для коррекции внешних проявлений и улучшения общего состояния кожи, волос, ногтей; охлаждающие жилеты, пульверизаторы, кондиционеры и частое питье при риске развития гипертермии у пациентов с ГЭД; использование кератолитиков на участках гиперкератоза у пациентов с синдромом Клоустона.

В таблице 3 представлены этапы реабилитации этой категории пациентов в условиях стационара ФГБУ НМИЦ «ЦНИИС и чЛХ».

\section{Прогноз}

Пациенты с ЭД обычно имеют хороший прогноз. Под влиянием лечения возможно уменьшение выраженности клинических признаков. Однако если есть задержка в диагностике уровень смертности для Х-ГЭД состав- 
ляет до $2.1 \%$ в течение первого года жизни в результате гипертермии. Общий уровень смертности от ЭД составляет примерно 30\% в течение первых 2 лет жизни из-за лихорадки или инфекций органов грудной клетки [8]. Продолжительность жизни взрослых, как правило, не изменена.

\section{ЛИТЕРАТУРА}

1. P. García-Martín A. Hernández-Martín 囚A. Torrelo Ectodermal Dysplasias: A Clinical and Molecular Review. Actas Dermosifliogr.2013;104:451-70.

2. Freire-Maia N. Ectodermal dysplasias. Hum Hered. 1971;21:309-312.

3. Freire-Maia N. Ectodermal dysplasias revisited. Acta Genet Med Gemellol (Rome). 1977;26:121-131.

4. Priolo M, Lagana C. Ectodermal dysplasias: a new clinical-genetic classification. J Med Genet. 2001;38(9): 579-585.

5. Priolo M. Ectodermal dysplasias: an overview and update of clinical and molecular-functional mechanisms. Am J Med Genet A. 2009;149A(9):2003-2013.

6. Nguyen-Nielsen M, Skovbo S, Svaneby D et al. The prevalence of X-linked hypohidrotic ectodermal dysplasia (XLHED) in Denmark, 1995-2010. Eur J Med Genet. 2013;56(5), 236-242.

7. Wohlfart S, Hammersen J, Schneider H et al. Mutational spectrum in 101 patients with hypohidrotic ectodermal dysplasia and breakpoint mapping in independent cases of rare genomic rearrangements. J Hum Genet. 2016;61(10):891-897.

8. Halai T, Stevens C. Ectodermal Dysplasia: A Clinical Overview for the Dental Practitioner. Dent Update. 2015;42(8):779-780, 783-784, 787-788 passim.

9. Cluzeau C, Hadj-Rabia S, Jambou M, et al. Only four genes (EDA1, EDAR, EDARADD, and WNT10A) account for $90 \%$ of hypohidrotic/anhidrotic ectodermal dysplasia cases. Hum Mut. 2011;32:70-72.

10. Мордовцев В.Н., Мордовцева В.В, Мордовцева В. В. Наследственные болезни и пороки развития кожи. Атлас. Наука, 2004.

11. Суколин Г. И. Клиника наследственных дерматозов. Атлас-справочние. БИНОМ, 2014.

12. Clarke A, Phillips D I, Brown R et al. Clinical aspects of X-linked hypohidrotic ectodermal dysplasia. Arch Dis Child. 1987;62:989-996.

13. Cacueto J, Zafra-Cobo MI, Ciria S, Unamuno P, Gonzalez-Sarmiento R: A novel EDA gene mutation in a Spanish family with X-linked hypohidrotic ectodermal dysplasia (in Spanish). Actas Dermosifiliogr 102: 722-725 (2011).

14. Trzeciak W H, Koczorowski R. Molecular basis of hypohidrotic ectodermal dysplasia: an update. J Appl Genetics. 2016;57(1):51-61.

15. Savasta S, Carlone G, Castagnoli R et al. X-Linked Hypohidrotic Ectodermal Dysplasia: New Features and a Novel EDA Gene Mutation. Cytogenet Genome Res. 2017;152(3):111-116.

16. Agarwal N, Singh PK, Gupta K et al. Identification of GJB6 gene mutation in an Indian man with Clouston syndrome. Indian J Dermatol Venereol Leprol. 2016;82:697700.

() Пономарев Артемий Эрнестович ( ponomarev_100@list.ru ), Йигиталиев Шухрат Нуманович, Буцан Сергей Борисович, Лебедев Валентин Витальевич, 